\title{
A redução da escola: a avaliação externa e o aprisionamento curricular ${ }^{1}$
}

\section{Schools' reduction: external assessment and curriculum imprisonment}

\author{
Maria Teresa Esteban ${ }^{2}$ \\ Andréa Rosana Fetzner ${ }^{3}$
}

\begin{abstract}
RESUMO
O trabalho apresenta pesquisas que abordam os reflexos da avaliação externa na organização do trabalho docente e nas práticas curriculares. A consolidação de um sistema nacional de exames é percebida como parte dos processos que produzem a subalternidade em confronto com propostas de democratização da escola pública. Problematiza-se a concepção de qualidade verificada nas políticas oficiais que atribuem à avaliação externa o poder de melhorar as práticas de aprendizagem-ensino e as bases de definição das finalidades e processos considerados legítimos na escola e suas relações com a produção de resultados escolares desiguais que historicamente penalizam crianças dos grupos sociais subalternizados. As práticas cotidianas colocam em tensão essa relação: dos objetivos das políticas públicas, razoavelmente afirmados pelas escolas em seus projetos pedagógicos, de democratização da educação escolar, com as ações escolares em que predominam exercícios de treinamento para as provas e propostas curriculares com objetivos padronizados e fragmentados. Os resultados aferidos pelos exames lidos à luz de perspectivas contra-hegemônicas levam à indagação desse sistema e do projeto que o sustenta.
\end{abstract}

Palavras-chave: avaliação; currículo; cotidiano escolar; subalternidade.

DOI: $10.1590 / 0104-4060.41452$

1 Trabalho financiado pela Fundação Carlos Chagas Filho de Amparo à Pesquisa do Estado do Rio de Janeiro e Conselho Nacional de Desenvolvimento Científico e Tecnológico.

2 Universidade Federal Fluminense. Faculdade de Educação. Campus Gragoatá. Niterói, Rio de Janeiro, Brasil. Rua Prof. Marcos Valdemar de Freitas Reis, s/n, Bloco D, Gragoatá. CEP: 24210-201.E-mail: mtesteban@uol.com.br

3 Universidade Federal do Estado do Rio de Janeiro. Escola de Educação. Rio de Janeiro, Rio de Janeiro, Brasil. Av. Pasteur, nº 458, 4 andar. Urca. CEP: 22.290-240.E-mail: akrug@uol.com.br 


\begin{abstract}
This work shows researches considering the reflections of external assessment in the organization of teachers' work and curricular practices. The consolidation of a national system of exams is perceived as part of the processes in which the democratization of state schools is articulated with the production of subalternity. The paper discusses the conception of quality verified in the official policies that attribute to external assessment the power to improve the teaching-learning practices and the bases for purposes definition, processes that are considered legitimate at school and their relations with the production of unequal school results that historically penalize children from subaltern social groups. The quotidian practices put in tension this relationship: public policies goals that are reasonably established by schools in their pedagogical projects and democratization of school education coexisting in the scholar actions in which there is a predominance of training exercises for the exams and the curriculum propositions through standardized and fragmented objectives. The results assessed by the exams read in the light of counter-hegemonic perspectives lead to interrogations about this system and the project that supports it.
\end{abstract}

Keywords: assessment; curriculum; scholar quotidian; subalternity.

Este trabalho apresenta estudos desenvolvidos sobre as repercussões da avaliação externa na organização do trabalho docente ${ }^{4}$ e nas práticas curriculares de uma rede pública de educação municipal ${ }^{5}$, em um contexto em que os diagnósticos oficiais continuam expondo um grande número de crianças que não revelam uma aprendizagem satisfatória. A escola analisada faz parte de uma rede de ensino que vem sofrendo pressão por resultados educacionais que priorizem a leitura, a escrita e o cálculo, na busca de melhores classificações nas avaliações externas.

No caso que tratamos aqui, o governo municipal implementou a aplicação de provas bimestrais, a todos os alunos da rede pública municipal, elaboradas pela Administração Central. Como complemento à medida, também disponibilizou para as escolas Cadernos de reforço escolar, que apresentam atividades destinadas a treinar os alunos para a realização das provas. Este governo municipal inicia o processo avaliativo com a crítica ao governo anterior, o qual acusa de praticar a aprovação automática dos alunos. O processo avaliativo externo toma fôlego no decorrer do ano de 2009 com a implementação de metas e prêmios

4 Pesquisa financiada pelo Conselho Nacional de Desenvolvimento Científico e Tecnológico.

5 Pesquisa financiada pela Fundação Carlos Chagas Filho de Amparo à Pesquisa do Estado do Rio de Janeiro. 
de desempenho para professores e funcionários (com base nos resultados dos alunos nas provas), simulados (provas) em ginásios de esportes, para toda a rede escolar, e parcerias com instituições públicas e de direito privado ${ }^{6}$ responsáveis pela implementação de programas específicos de reforço escolar.

Em nossa perspectiva, o enfrentamento da evidente insuficiência da aprendizagem de muitas crianças em seu percurso de escolarização precisa ser realizado com a indagação das bases de definição das finalidades e processos considerados legítimos na escola e suas relações com a produção de resultados escolares desiguais que historicamente penalizam crianças dos grupos sociais subalternizados. Igualmente é necessário considerar que a grande exposição dos resultados indesejáveis contribui para a invisibilidade de experiências cotidianas em que se tecem conhecimentos e aprendizagens, nem sempre traduzíveis nos parâmetros e escalas que estruturam o exame estandardizado.

Nosso compromisso com a democratização da escola pública, na busca de torná-la cada vez mais um lugar privilegiado para experiências emancipatórias, em que a ampliação do conhecimento seja parte do diálogo entre diferentes culturas, conhecimentos e sujeitos, nos faz, por meio da pesquisa com o cotidiano escolar, buscar compreender qualitativamente estas experiências, visibilizar conhecimentos e aprendizagens que, fora do alcance dos exames, possam afirmar a importância social da escola e indicar caminhos que possam contribuir com a ampliação de experiências de êxito.

Observa-se que o fracasso torna-se a centralidade do discurso sobre a escola, especialmente sobre a escola pública, o que destaca-se neste trabalho, porém, é a necessidade de maior atenção às pistas de que o êxito é uma possibilidade que ali se anuncia cotidianamente. Encontrar e fortalecer tais possibilidades, muitas vezes apagadas pela recorrência do fracasso escolar e por sua circunscrição sociocultural, demanda profunda reflexão sobre: os indicadores usados para a definição do que se denomina fracasso; a dinâmica sociocultural e econômica de sua produção; as proposições que pretendem sua superação; os processos explícitos e implícitos de desarticulação das possibilidades de êxito anunciadas; as aprendizagens realizadas e não validadas.

A dinâmica sucesso/fracasso tem como elementos articuladores a estratificação, o silenciamento da diferença e a justificativa da produção constante de formas de inclusão degradada. Os processos escolares, em suas dimensões

6 Sobre as relações entre o público e o privado, implicadas na contratação do Terceiro Setor para realização de um trabalho que seria de responsabilidade do Estado, provocando interferências privadas na condução da política pública e o desenvolvimento de práticas de quase mercado ver a pesquisa de PERONI, Vera. Reconfigurações do estado: conexões entre o público e o privado. 2008. Disponível em: <http://www.ufrgs.br/faced/peroni/>. Acesso em: 11 out. 2010. 
micro e macroestruturais, guardam vínculos com movimentos de manutenção do histórico processo de colonialidade do poder (MIGNOLO, $2003^{7}$ apud COSTIN, 2009b, p. 15), em que são urdidas práticas sociais, rearticulando as relações de subalternização. Porém, não se pode desconsiderar que ações e enfrentamentos escolares produzem tensões nessa relação e promovem algumas (pequenas) rupturas nas relações consolidadas. Entendemos que a ênfase no desempenho estudantil, tomado como principal indicador da qualidade da escola pelo atual sistema de exames, amplifica a ambivalência (BHABHA, 1998) das práticas escolares cotidianas, na medida em que o discurso sobre a escola e da própria escola elege como percurso de sucesso aquele tecido pelos processos de subalternização, que operam como redutores de possibilidades efetivas de aprendizagem.

Os resultados escolares se mostram significativos para a investigação dos processos instaurados e dos procedimentos e instrumentos utilizados como artefatos que produzem relações e discursos presentes na dinâmica de avaliação e que se entretecem aos modos como os sujeitos vivem a avaliação e dialogam com seus percursos e resultados.

Com esses entendimentos e compromissos desenvolvemos este trabalho com base em estudos sobre o impacto das políticas de avaliação na formulação das práticas cotidianas de avaliação da aprendizagem e na pesquisa por meio da qual se acompanhou, durante os anos de 2007 a 2010, uma escola de Ensino Fundamental municipal que atende a crianças de 6 a 12 anos, na zona sul carioca.

A seguir apresentaremos nossa perspectiva na leitura dos processos e discursos propostos por meio das políticas contemporâneas de avaliação sobre a escola, as indagações que fizemos com o cotidiano escolar acompanhado e as conclusões que até este momento podemos tomar como aspectos da redução da escola.

\section{Os indicadores usados para a definição do que se chama fracasso}

Dados apresentados pelo Instituto Nacional de Estudos e Pesquisas Educacionais Anísio Teixeira - INEP sobre o desempenho dos estudantes, aferido pelo Sistema de Avaliação da Educação Básica - SAEB, oferecem informações importantes para o aprofundamento da reflexão sobre os processos de avaliação

7 MIGNOLO, W. Histórias locais/Projetos globais: Colonialidade, Saberes Subalternos e Pensamento Liminar. Belo Horizonte, MG: UFMG, 2003. 
educacional, em especial os que se baseiam em exames estandardizados. Em documento apresentado pelo INEP (2007) confirmava-se a tendência de queda no desempenho, já verificada em relatório anterior: "Desde o início da série comparável, a média de proficiência no Brasil está abaixo do mínimo satisfatório. Isso ocorreu em todos os ciclos de avaliação [...] revelando uma queda constante nas proficiências médias". (INEP/MEC, 2007, p. 33).

A constante redução nas médias de proficiência não abala o discurso constituído no âmbito da pedagogia do exame $e^{8}$ (BARRIGA, 2004), preservando os procedimentos de avaliação externa de questionamentos mais profundos. Conserva-se a generalização, que facilita que ideias como qualidade, equidade e eficiência, estruturantes do sistema de exames estandardizados, recebam significados diversos, segundo os contextos em que são enunciadas, além de priorizar a dimensão individual dos resultados escolares, por meio dos destaques dados à insuficiência do desempenho dos estudantes. Este desempenho, também uma generalização, pode ser interpretado como consequência de problemas do próprio estudante, da incompetência docente (frequentemente matizada pelo discurso da "má formação profissional") ou da ineficiência da unidade escolar (também individualizada).

Como campo de pesquisa, tomamos uma escola pública de Ensino Fundamental de um município que possui 1.063 escolas de Ensino Fundamental e 553.411 alunos (dados do $1^{\circ}$ semestre de 2009, site da Secretaria). A escola em que se desenvolveu a pesquisa foi acompanhada entre 2007 e $2010 \mathrm{com}$ a participação de 30 estagiários de Ensino Fundamental no ano de 2009, os quais forneceram 12 relatórios de estágio para a pesquisa. Além do acompanhamento dos estagiários, no ano de 2009 foram assistidas parcialmente 12 aulas comuns e 28 atividades práticas desenvolvidas pelos estagiários, e promoveram-se quatro reuniões com a direção e coordenação da escola. Em 2010, foram entrevistadas na escola pesquisada cinco professoras, a diretora, a coordenadora pedagógica, quatro alunos e uma mãe de aluno.

No município a que a escola estudada pertence, o discurso sobre o poder das provas para melhoria da aprendizagem é associado a uma determinada "concepção de gestão pública", com metas definidas e mensuração de resultados. Para melhorar seus resultados, "[...] cada escola assinou um contrato em que se compromete não a atingir, mas a buscar determinadas metas" ${ }^{\prime 10}$. Assim

8 Para o autor, o modelo dominante de avaliação educacional atua no sentido de inscrever as práticas pedagógicas à lógica do exame, tecnologia disciplinar constituída que dá visibilidade, vigia e sanciona os sujeitos para normalizá-los, segundo demandas do modelo de sociedade hegemônico.

9 Declaração da Secretária de Educação, site da Secretaria. Disponível em: <http://www. rio.rj.gov.br/sme/destaques/artigos.html>. Acesso em: 09 set. 2009.

10 Pronunciamento da Secretária no jornal O Globo, 06/09/2009, p. 15. 
direcionado, este dircurso sobre a escola assume como causas para o aludido fracasso escolar: as famílias desestruturadas e sem acesso ao saber letrado ${ }^{11}$ (problema do próprio estudante), a falta de orientação ao docente sobre o que ele precisa fazer para que seus alunos aprendam (portanto, má formação profissional, afirmada pela Secretaria de Educação, na necessidade de que esta informação seja gerada por meio de cadernos de reforço escolar, capazes de resolver o problema) e gestão por resultados (a ser implementada pela escola que, supostamente, sem o plano de metas e resultados, não saberia o que fazer). Embora o fracasso de muitas crianças torne-se fato corriqueiro e suas explicações sejam naturalizadas, percebemos que este ainda produz angústia, tristeza e indignação no cotidiano escolar.

Os estudantes e os docentes são descontextualizados, apartados dos processos que conformam a dinâmica aprendizagem-ensino ${ }^{12}$ de que participam, desconsiderados como sujeitos da aprendizagem e do conhecimento e reduzidos a denominações referidas a níveis de desempenho: seus rostos, corpos, gestos, vozes e conhecimentos são desvitalizados e traduzidos em competências, indicadores, gráficos e dados, enfim, fragmentos quantificáveis.

Em oito das doze aulas observadas, a prática docente reproduz o discurso oficial para com os alunos: é necessário disciplinar e treinar o corpo e a mente, em classes enfileiradas, proibir a conversa e, em muitas ocasiões, realizar exercícios que exigem, inúmeras vezes, o mesmo raciocínio para sua solução. Atividades que envolvem a solução de operações matemáticas de adição (e que envolvem o mesmo exercício: soma com transporte), por exemplo, são propostas em um tempo que ocupa as crianças por duas das quatro horas de duração da aula. Atividades como esta indicam a ênfase na perspectiva mecanicista, em que se fortalecem os processos de treinamento e reprodução de fragmentos do conteúdo. A inserção das provas externas, acompanhada da pressão pela competição na busca de um melhor IDEB para a escola, fortalece a ideia de treinamento no trabalho com o conhecimento escolar.

Estabelece-se uma relação linear entre exame - processo de coerção, certificação e exclusão - e aprendizagem, na qual emerge a individualização, compatível com a diversidade esperada, e rasura-se o sujeito, expressão da diferença $\mathrm{a}^{13}$. Fortalecem-se práticas e discursos que não problematizam os procedimentos escolares e que negam aos estudantes o acesso aos conhecimentos,

11 Idem.

12 Demarcamos com esta expressão a indissociabilidade entre a aprendizagem e o ensino, tomando como centralidade a aprendizagem.

13 Sobre a relação entre diversidade e diferença, ver Bhabha (1998) e Skliar (2003). 
desvalorizam seus saberes ou não reconhecem sua capacidade de aprender e de produzir conhecimentos válidos.

$\mathrm{O}$ jogo enunciativo produz um discurso que induz à necessidade de mais exame para se alcançar o objetivo almejado: "Como o IDEB só sai a cada dois anos, o município está preparando seu IDEB [próprio] - com testes para alunos do $3^{\circ}$ e do $7^{\circ}$ anos - , que será divulgado ao final de cada ano. Com isso, será possível montar uma série histórica da evolução dos estudantes." ${ }^{14}$

Entendemos que o exame, assumido aqui como a aplicação dos testes padronizados que se propõem a medir o desempenho escolar, apresenta, em sua proposta, um contrassenso do que, no campo dos estudos das políticas educacionais em avaliação, temos entendido como função da avaliação. Na medida em que se rompe com a multirreferencialidade dos processos avaliativos (sua complexidade e a diversidade de questões que estão envolvidas na promoção da aprendizagem-ensino), torna a aplicação dos exames um trabalho inócuo, do ponto de vista da promoção da qualidade da educação oferecida, ao mesmo tempo que investe e promove concepções e práticas tecnicistas que corroboram com percepções lineares sobre os processos de aprendizagem.

No campo da política educacional, pesquisadores como Apple e Buras (2008) e Afonso (2005) têm apontado como as políticas de avaliação alinhadas com a proposta do Estado-avaliador têm fracassado na promoção da qualidade educacional e contribuído com o aumento da desigualdade.

Apple e Buras (2008) reiteradamente têm indicado que as políticas que promovem os exames, no caso estadunidense, são frutos de uma aliança entre os liberais que aplicam à escola os princípios do livre-mercado, isto é, a defesa da imagem dos pais como consumidores dos produtos educacionais, situação em que os exames funcionam como controle de qualidade do produto a ser consumido - a educação e os conservadores, estes lutando pela manutenção e controle dos "[...] fundamentos culturais e morais da nação, temendo a perda da coesão nacional ou a perda de almas" (APPLE; BURAS, 2008, p. 14), como resultado, determinados conhecimentos são valorizados e outros subalternizados.

Para Afonso (2005):

[...] a emergência do Estado-avaliador] traduz um retrocesso considerável, não apenas porque promove a recuperação e atualização de muitos dos pressupostos positivistas e quantitativistas tornados anacrônicos pelo próprio aperfeiçoamento das teorias da avaliação, mas sobretudo porque, do nosso ponto de vista, favorece a desvalorização da multireferencialidade

14 Declaração da Secretária, O Globo, 06/09/2009. 
dos processos avaliativos, que tem vindo a ser reconhecida como o novo ponto de chegada para superar a crise dos paradigmas tradicionais neste domínio. (AFONSO, 2005, p. 128).

A relação entre exame e qualidade se constitui verdadeira como efeito da circulação do poder, que atravessa as dinâmicas escolares e sociais, promovendo formas de saber e desejos que se plasmam na produção de projetos assumidos como individuais. A inscrição da pedagogia do exame no regime de verdade sobre os vínculos entre escolarização, classificação e inserção social oculta que os resultados aferidos contrariam o objetivo central do projeto oficial de avaliação educacional, de que a consolidação e o refinamento do sistema de exames se traduzam em "ampliação da qualidade".

Observamos a ampliação do sistema de avaliação externa, por meio de testes estandardizados, que se expressa pela criação de mais um exame nacional de larga escala, a Avaliação Nacional da Alfabetização (ANA), aprofundando os mecanismos de controle e redução dos processos de ensino e de aprendizagem desde o início da vida escolar propostos pela Provinha Brasil, e pela instituição de exames de larga escala para sistemas estaduais ou municipais, como o que abordamos neste trabalho. Diante dos índices insuficientes do IDEB, antecipa-se e amplia-se a inserção das crianças no sistema de avaliação externa. A avaliação permanece proposta como um procedimento técnico, vinculado à mensuração e controle, realizado por instrumentos unificados.

Embora os documentos oficiais afirmem como finalidade das provas o monitoramento do processo pedagógico realizado nas escolas públicas, por meio de um diagnóstico utilizado na prevenção e correção de possíveis insuficiências, o efeito do diagnóstico induzido e organizado em uma escala rígida e previamente determinada é a produção de resultados que diferenciam - para hierarquizar - contextos, processos, resultados e sujeitos, confluindo para as perspectivas apontadas por Barriga (2004) e Afonso (2005).

O desempenho dos estudantes nesses testes e a sua desejada melhora são interpretados como questões predominantemente técnicas, desconsiderando-se a complexidade dos processos escolares cotidianos e seus entrelaçamentos com a dinâmica sociocultural. Entretanto, o diagnóstico superficial decorrente da verificação do rendimento serve como referência para que o governo municipal, por sua vez, envie bimestralmente orientações curriculares às escolas e, junto com as provas padronizadas, indicações sobre como trabalhar os conteúdos necessários. Como declara a Secretária de Educação: "Num certo sentido, estamos centralizando um pouco a política educacional e dando autonomia de 
gestão às escolas na ponta para trabalhar com metodologias, descobrir soluções". (COSTIN, 2009b, p. 15).

Entendemos que essa simplificação não se circunscreve ao município que focalizamos neste trabalho, pois o próprio documento que apresenta a Provinha Brasi $1^{15}$ mostra as provas estandardizadas como um mecanismo que provoca redução na dimensão sociocultural do processo de alfabetização. A avaliação da aprendizagem é substituída pela mensuração daquilo que pode ser aferido por um teste de múltipla escolha, aplicado, em todo território nacional, a crianças com aproximadamente oito anos:

Como nem todas as habilidades a serem desenvolvidas durante o processo de alfabetização são passíveis de verificação por meio da Provinha Brasil [...], foi necessário selecionar algumas dessas habilidades para construir o teste.

Assim, as habilidades definidas para avaliar a leitura e a escrita são aquelas que podem dar informações relevantes em função dos objetivos propostos e das condições impostas no âmbito desta avaliação. (INEP/ MEC, 2009, p. 11-12).

Essa perspectiva se mantém nos demais exames nacionais e se expressa também nos exames municipais por nós estudados. O discurso construído sobre o fracasso da educação escolar na cidade afirma o fracasso da escola, gerando a necessidade de um controle sobre o que fazem e o que estudam os alunos, ao ponto de, na Administração Central, elaborarem-se as provas bimestrais e a orientação da aplicação de exercícios como treinamento para as provas.

Esse discurso, ao nosso ver, reduz a escola. Reduz seu papel social, de (1) integração de diversos saberes e culturas em diálogo, de (2) campo de disputa entre intencionalidades educativas, de (3) espaço de formação intelectual. Interessa-nos levantar, diante de um quadro que busca o controle permanente da escola, os saberes em disputa, o estudo das interações cotidianas, expectativas, negociações, improvisações próprias da língua ordinária. (CERTEAU, 2008).

Questionadas sobre as relações entre as avaliações externas nas suas práticas docentes, as professoras indicaram:

15 Nessa discussão trazemos concepções presentes na Provinha Brasil por ser o primeiro exame nacional a que as crianças são submetidas, portanto, significativo na demarcação da perspectiva de leitura, escrita e matemática que orienta a ação escolar. Dialogamos também com as provas em larga escala realizadas pelo município estudado e aplicadas ao $5^{\circ}$ ano do Ensino Fundamental. 
Olha, eu acho que ela [a gestão atual] está dando mais visibilidade para o trabalho dela e eu acho que ela tem ficado muito preocupada com os resultados e o meu medo é que esses resultados sejam amarrados, por mais que note uma preocupação que ela tá assim mais de perto... eu acho também que esse material que eles tão fazendo ajuda, mas eles tão dando coisa demais e a gente não tá conseguindo dá conta de tanto material que eles mandam, caderno pedagógico, sabe, você tem outras coisas para ver, mas você tem que deixar o que te vendo para dar mais ênfase aos cadernos pedagógicos porque as provas são baseadas no caderno pedagógico e a avaliação da escola é baseada na avaliação que vem dessas provas... então, é o que eu te falei antes, não dá para você ousar tanto... (PROFESSORA ANA $\left.{ }^{16}, 2010\right)$.

Em alguns casos, alguns alunos que são MB [que tiram conceitos Muito Bons] fazem a prova e acertam todas as questões e eles estão conscientes do que eles estão realizando, mas em outros casos não, o aluno tem o conceito " $R$ " [Regular] e acertou quase tudo, às vezes eles têm muita dificuldade de fazer essas provas, pricipalmente as de lingua portuguesa que são muito grandes todas com um média de um texto para cada duas questões, e ai eles cansam, até porque é uma turma que tem o desenvolvimento menor e eles têm pouco hábito de leitura, a gente trabalhou isso, mas eles ficam cansados quando é uma questão de prova. (PROFESSORA ELISA, 2010).

Essas construções sociais, bem como as práticas e as percepções estão implicadas em sentidos que se constroem diferentes, entre sujeitos: a intensidade do discurso sobre o fracasso escolar, e das práticas avaliativas que neste discurso se sustentam (e que neste momento pressionam a escola estudada), engessa suas práticas curriculares e pouco contribui para uma proposta educacional mais crítica, autônoma ou participativa, valores comumente anunciados nos projetos escolares.

Não se discute o quanto a fragmentação impede a expressão do conhecimento, para permitir seu enquadramento nas questões de múltipla escolha que pretendem garantir uniformidade, neutralidade e objetividade na correção e na interpretação dos dados. Como este conhecimento fraturado e descontextualizado não pode ser aprendido ou avaliado, opta-se por mensurar objetivos alcançados, propostos como descritores de habilidades adquiridas ou a se adquirir. Entende-se

16 Os nomes são fictícios para assegurar o anonimato dos entrevistados. 
que o somatório das habilidades verificadas expressa a aprendizagem e o conhecimento do sujeito. A "insuficiência” dessa mensuração não é posta em discussão.

O discurso articulado ao sistema de exame apresenta o baixo desempenho como ausência de aprendizagem e de conhecimentos válidos, o que produz vínculos entre a diferença nos resultados escolares e as justificativas socialmente aceitas para a marginalização ${ }^{17}$. A elevação do rendimento escolar como procedimento socialmente validado de redução das desigualdades sociais mais uma vez desconsidera a complexa dinâmica social de produção/manutenção dos processos de subalternização. A avaliação é conduzida pelo posicionamento dos estudantes numa escala: a diferença - "insuficiência" a ser "corrigida" - é claramente assumida como indicador de desigualdade, portanto a mantém.

A dimensão classificatória da avaliação educacional sustenta a seleção e, consequentemente, a negação dos percursos, conhecimentos e sujeitos mal avaliados. Produzem-se espaços onde ao inscrever as diferentes crianças, com os seus diferentes conhecimentos/desempenhos, criam-se possibilidades de exclusão dentro do próprio sistema. A escola ao abrigar as crianças sem interpelar os processos de exclusão também incrementa a possibilidade de que aquelas que não espelham a imagem proposta ganhem visibilidade como o outro - aquele que não corresponde ao modelo idealizado. Criam-se novas possibilidades de exercício do controle autoritário, tradicionalmente presente nas práticas de avaliação classificatória. O reconhecimento da singularidade e da pluralidade que expõem a diferença pode ser parte do processo de sua negação através de sua classificação, ordenação e controle, como parte de um processo de subalternização. O projeto de qualidade que sustenta esse processo partilha uma concepção excludente das dinâmicas escolar, socioeconômica e cultural, portanto, não responde às exigências de uma escola pública democrática, comprometida com as classes populares.

\section{O aprisionamento curricular}

Do lugar da pesquisa desenvolvida, entendemos que os discursos que tratam das avaliações externas engessam a escola, definem o conteúdo escolar como treinamento da leitura, da escrita e do cálculo e, com isso, destituem:

17 Aqui, marginalizar tem o sentido de colocar à margem, sem o matiz de criminalidade que, com frequência, se plasma a essa palavra. 
a) a leitura, a escrita e o cálculo de sua função social, de sua utilização no desenvolvimento da sociedade, transformam em objeto da aprendizagem o que seria um instrumento da aprendizagem, ou seja, ao insistir na abordagem mecânica destas atividades e com a utilização de exercícios maçantes, descolam estes conteúdos do seu sentido social: a comunicação de ideias e a organização das informações, por exemplo. Como afirma Smolka (2003, p. 17): "[...] tudo o mais é interrompido e suspenso em prol do ensino da leitura e da escrita. As atenções se concentram na escrita como uma complicada habilidade motora a ser desenvolvida $[\ldots] "$ ".

b) a escola de sua função social. Ao definir externamente o conteúdo da escola (por meio da política de exames), impede-se a escola de pensar-se, fazer-se, propor-se, enquanto um projeto coletivo da comunidade, das famílias e dos educadores que dela participam. A escola é ocupada por treinamentos para a prova, com exercícios que não apresentam a discussão de questões que possam ser consideradas interessantes pelos alunos ou relevantes para a comunidade. Não há espaço para a reflexão, mas para o exercício. As provas externas chegam prontas da Secretaria de Educação do município e, fora isto, os alunos são chamados aos simuladões que buscam preparar para a Prova Brasil e ao preenchimento dos cadernos de reforço escolar e do livro didático. O bom desempenho nas provas transforma-se em objetivo e fim da escola.

A orientação curricular a que está submetida a escola não difere dos objetivos (apresentados como descritores pelo governo municipal) para as provas. Por exemplo, no $5^{\circ}$ ano, consta dos descritores do Ensino Fundamental em Língua Portuguesa, para o $3^{\circ}$ bimestre:

[...] localizar informações explícitas em um texto; identificar o tema de um texto; estabelecer relação causa/consequência entre partes e elementos de um texto; reconhecer diferentes formas de tratar uma informação na comparação de textos que tratam do mesmo tema, em função das condições em que ele foi produzido e daquelas em que será recebido [...]. (SME, 2009, p. 6).

Comum à crítica dessa organização curricular por objetivos, é que estes variam entre o óbvio (a leitura de um texto pressupõe que ele diga alguma coisa e que a prática da leitura implique lhe atribuir significados), e o impossível (que todos atribuam o mesmo significado a um texto lido). Ressaltamos que os limi- 
tes são dados (para o que possa configurar-se em sentido aceito pelo docente, para um texto) pela prática insistente em que o mesmo texto tenha apenas um sentido, em qualquer situação, e para qualquer leitor.

No que se refere aos sentidos dos textos, inúmeras situações foram acompanhadas: desde a dificuldade de alguns alunos em interpretar as ordens de exercícios do livro didático (onde fomos orientados pelo docente que o aluno não poderia ser ajudado para esta compreensão, porque nas provas ele não pode ser ajudado), até a interpretação docente de que, ao escrever abaixo de um desenho de uma borboleta, um porco e uma flor, borboletinha, porquinho e florzinha, respectivamente (exercícios de uma das provas bimestrais observadas na escola), a aluna teria errado a escrita porque usava o diminutivo, que não era esperado como resposta válida naquele momento.

Os resultados que norteiam a composição do sistema de exames expressam a manutenção do fracasso escolar, porém, são superficialmente considerados pelas políticas oficiais, que ressaltam quase que exclusivamente sua dimensão técnica. As propostas formuladas não parecem incorporar os resultados escolares insatisfatórios como expressão da exclusão das crianças das classes populares do direito à sistemática ampliação e complexificação de seus conhecimentos por meio do diálogo com os saberes veiculados pela escola. Simplifica-se o problema e, consequentemente, não se atua sobre as complexas relações implicadas na dinâmica fracasso/sucesso escolar. A redução da questão é de tal ordem que fraciona a perspectiva estritamente pedagógica, elegendo para as questões das provas os aspectos mais superficiais dentro do restrito campo das habilidades e competências escolares.

Quais são os percursos de aprendizagem realizados pelas crianças? Uma questão de múltipla escolha pode dar informações significativas sobre os processos de aprendizagem das crianças? E sobre a relação aprendizagem-ensino? Por que uma criança "escolhe" a opção "certa"? Por que "escolhe" uma das opções "erradas"? Quais as diferenças de conhecimento e de aprendizagem entre essas opções?

Somente por uma simplificação do processo aprendizagem-ensino pode-se aceitar níveis de desempenho como tradução de aprendizagem. Portanto, a elevação desses níveis não representa necessariamente uma proposta de ampliação significativa do conhecimento pela criança. Mais distante ainda fica de se relacionar à alteração na condição subalterna dos sujeitos, que deveria ser a principal finalidade de um processo democrático de escolarização. Entretanto, questionar o modelo de qualidade assumido não significa abrir mão do compromisso com a apropriação crítica e aprofundada do conhecimento, pois ele é um instrumento indispensável às lutas pela emancipação social. 
A escola, percebida como espaço de ampliação permanente dos conhecimentos, pode ser vivenciada como lugar de dúvidas, erros, confrontos, encontros, acertos, diálogos, limites, desafios, possibilidades. Com as inabilidades, incompetências, desconhecimentos, ignorâncias, impossibilidades - expressões de resultados que exigem a continuidade dos processos.

Como enquadrar as crianças - e cada criança - em seu processo de chegada ao mundo, de indagação da vida, de compreensão da vida, de produção da vida...? Como enquadrar a criança que interroga e se interroga, e não encontra respostas, ou não se satisfaz com as respostas, ou se desinteressa da resposta porque outra pergunta torna-se mais urgente, porque ainda não formulada? Como enquadrar a criança descobrindo a escrita, se inserindo na cultura escrita, tecendo conhecimentos sobre a escrita como parte de um modo de ser e estar no mundo, se reconhecendo como produtora de escrita e de sentidos?

$\mathrm{O}$ que a inscrição das crianças nos níveis considerados inadequados ao seu tempo de escolarização significa? O que significam as respostas dadas pelas crianças que aí estão, para as próprias crianças que as deram? O que negam os "níveis insuficientes"? O que promovem? O que esse processo introduz/impede na dinâmica aprendizagem-ensino?

Nos cadernos de reforço escolar encaminhados às escolas da rede municipal em foco neste trabalho, encontra-se, por exemplo, o texto chamado "Vaca amarela", de Sérgio Caparelli, que parcialmente transcrevemos a seguir: "Vaca amarela/fez cocô na panela,/cabrito mexeu, mexeu, quem falar primeiro/comeu o cocô dela. Vaca amarela,/sutiã de flanela,/cabrito coseu, coseu quem se mexer primeiro/pôs o sutiã dela [...]."

Os exercícios que se seguem propõem que os alunos sublinhem no texto as palavras que rimam, e uma brincadeira de rimar: a) Vaca levada/Caiu da . b) Vaca mimosa/De batom cor de [...].

O que esse texto indica para o processo de aprendizagem-ensino? É possível que todas as crianças que sublinhem a última palavra dos dois primeiros versos e a última palavra do último verso, em cada estrofe, tenham aprendido o que é rima? É possível que as crianças que não sublinhem estas palavras não conheçam o que é uma rima? Por que a leitura, a escrita e a rima não podem ser trabalhadas em situações de estudo sobre temas que tenham relevância para a criança? Quantas interpretações ou mesmo incompreensões são possíveis neste texto? Qual o espaço para a criança dizer (se assim entendesse) que a vaca levada caiu tiroteada?

Os padrões propostos classificam desempenhos, mas, obviamente se estendem aos sujeitos, pois configuram modelos ideais que devem ser alcançados, que têm se revelado pouco favoráveis aos estudantes das classes populares, embora estimulados pelas políticas públicas em curso. O foco no desempenho e 
a classificação atuam sobre os estudantes como uma estratégia de disseminação e detalhamento de saber e de poder sobre o outro. Negar o outro, aquele que expressa as fraturas do projeto de homogeneização, é uma exigência de uma sociedade desigual que precisa produzir uma imagem conveniente às práticas que subalternizam e marginalizam diversos grupos sociais, para realizar os processos de subalternização. Porém, a persistência da desigualdade indica a impossibilidade de completo enquadramento do outro e indica a existência de outros movimentos no cotidiano da escola que se democratiza.

A identificação e a exposição da diferença mostram-se práticas que facilitam a modelagem dos sujeitos, como estratégia de negação da alteridade, pois nem sempre produzem sua validação como conhecimento, não levam a uma valoração positiva dos sujeitos em sua diferença, tampouco interpelam a produção de desigualdades e suas relações com a diferença, na escola. A escolarização se relaciona aos processos sociais que oferecem aos sujeitos posições sociais valorizadas, os impelindo a substituir os conhecimentos, processos cognitivos e modos de viver produzidos em experiências socioculturais marginalizadas na dinâmica social hegemônica, por aqueles reconhecidos no processo de escolarização. Negar-se a si mesmo passa a ser parte dos processos de busca de legitimação escolar e social. Assim, a relação inclusão/exclusão pode ser relida como um complexo processo em que se inclui sempre, porém, em posições desiguais, numa instituição que "De tudo deseja apoderar-se, que tudo deseja conter e incluir, que não suporta as ausências, os esquecimentos, as ambivalências, e que repousa satisfeita ao fechar suas portas por dentro, ao enclausurar-se". (SKLIAR, 2003, p. 23). Esse enquadramento demanda uniformização das ações e dos resultados escolares, procedimentos compatíveis com o silenciamento de diversos grupos socioculturais, mantendo assim estreitos vínculos com a configuração e manutenção do poder colonial. (MIGNOLO, $2003^{18}$ apud COSTIN, 2009, p. 15).

\section{São possíveis outros caminhos?}

As ideias correntes no cotidiano escolar em que as diferenças de processos e de resultados são compreendidas como deficiências ressaltam correção dos percursos de aprendizagem e enquadramento dos sujeitos, e não uma redefinição

18 MIGNOLO, W. Histórias locais/Projetos globais: Colonialidade, Saberes Subalternos e Pensamento Liminar. Belo Horizonte, MG: UFMG, 2003. 
dos pressupostos que orientam as concepções e práticas curriculares hegemônicas. O exame, expressão dessa concepção, define os limites nos quais cada criança deve se movimentar.

Apesar dos esforços para capturar o outro, para definir, nomear e classificar tudo e todos, para colonizar territórios, povos e sujeitos, para impedir a descontinuidade, para mascarar a desordem, para modelar os desejos, para apagar a diferença e louvar a diversidade e a tolerância, os entre-lugares (BHABHA, 1998) se produzem, a diferença permanece, o híbrido inquieta ao expor sua inconformidade. No cotidiano escolar não se pode deixar de conviver com a diferença, mesmo que desqualificada e posta às margens do processo pedagógico, não integrada às práticas no sentido de favorecer a todos. No entanto, sua permanência contribui para a indagação dos limites do processo de democratização da escola instituído, inclusive em sua dimensão pedagógica.

As práticas escolares ancoradas na busca da homogeneidade não conseguem, nem se propõem a, apagar completamente as diferenças que constituem a sociedade e a escola. A negociação se plasma às práticas cotidianas, fazendo com que fragmentos diversos sejam incorporados aos seus movimentos, indicando a impossibilidade da completa exclusão da diferença desse contexto. A individualização dos processos e resultados emerge como uma estratégia para a ocultação das bases socioculturais dos processos pedagógicos e dos resultados escolares.

A ênfase nas ações e nos desempenhos individualizados ganha novos contornos com a consolidação desse sistema de avaliação externa. Os resultados aferidos se referem a cada sujeito, promovendo um desmembramento que dificulta a percepção das relações que os articulam. Sustentam discursos públicos que estimulam ações individualizadas, vistas como necessárias e suficientes para a elevação dos índices aos patamares propostos como expressão da ampliação da qualidade da escola, sem considerar os laços dos processos de escolarização com as redes socioculturais em que se tecem as diferentes dimensões da vida.

Os resultados alcançados nos exames e expostos nos rankings apresentam uma visão negativa da escola e se traduzem em políticas públicas cujos sentidos orientam a formatação da sala de aula. Porém, olhando a sala de aula de perto, a experiência escolar cotidiana com suas diferentes dimensões, em especial o que acontece em suas margens, encontramos a potência da sala de aula como espaço de formação, lugar de enunciação de muitas vozes e projetos, que não pode resumir a prática pedagógica à aplicação de modelos construídos a partir de espaços, discursos e lógicas reducionistas, avessos ao diálogo e à reflexão, que não contemplam a complexidade dos processos presentes em suas interações cotidianas. 


\section{REFERÊNCIAS}

AFONSO, A. J. Avaliação educacional - regulação e emancipação: para uma sociologia das políticas avaliativas contemporâneas. 3. ed. São Paulo: Cortez, 2005.

APPLE, M. A.; BURAS, K. L. (Orgs.). Currículo, poder e lutas educacionais: com a palavra, os subalternos. Porto Alegre, RS: Artmed, 2008.

BARRIGA, A. D. Uma polêmica em relação a exame. In: ESTEBAN, M. T. (Org.). Avaliação: uma prática em busca de novos sentidos. 5. ed. Rio de Janeiro: DP\&A, 2004. p. 51-82.

BHABHA, H. O local da Cultura. Belo Horizonte, MG: UFMG, 1998.

CERTEAU, M. A invenção do cotidiano. 1. Artes de Fazer. Petrópolis, RJ: Vozes, 2008.

COSTIN, C. Mensagem para as escolas. A educação carioca. 2009a. Disponível em: $<$ http://www.rio.rj.gov.br/sme/destaques/artigos.htm>. Acesso em: 09 set. 2009.

COSTIN, C. Metas para melhorar as notas do ensino: escolas municipais assinam contratos de gestão para buscar objetivos e superar problemas da aprovação automática. $O$ Globo, Rio de Janeiro, p. 15, 06 set. 2009b. Disponível em: <http://www.uff.br/geographia/ojs/index.php/geographia/article/viewFile/184/176>. Acesso em: 14 mar. 2013.

FETZNER, A. R. Conhecimento escolar: processos de inclusão e exclusão, movimentos curriculares e práticas avaliativas na escola de ensino fundamental. (Diário de pesquisa). Rio de Janeiro, 2009. (mimeo).

INEP/MEC. O desafio de uma educação de qualidade para todos: educação no Brasil - 1990-2000. Brasília, DF, 2004. Disponível em: <http:/www.publicacoes.inep.gov.br/ portal/subcategoria/4/page/1/item_page/75>. Acesso em: 14 mar. 2013.

INEP/MEC. Relatório Nacional SAEB 2003. Brasília, DF, 2006. Disponível em: <http:// portal.inep.gov.br/publicacoes-saeb>. Acesso em: 01 out. 2014.

INEP/MEC. SAEB/2005 - Primeiros resultados: Médias de desempenho do SAEB/2005 em perspectiva comparada. 2007. Disponível em: $<$ http://portal.inep.gov.br/publicacoes-saeb>. Acesso em: 14 mar. 2015.

INEP/MEC. Provinha Brasil - Passo a passo. 2009. Disponível em: <http://provinhabrasil.inep.gov.br/images/stories/html/documentos/passo_a_passo_1_2009pdf>.Acesso em: 14 mar. 2015.

PERONI, V. Reconfigurações do estado: conexões entre o público e o privado. 2008. Disponível em: <http://www.ufrgs.br/faced/peroni/>. Acesso em: 01 out. 2014.

RIO DE JANEIRO. Secretaria Municipal de Educação do Rio de Janeiro. Cadernos de Reforço Escolar. Língua Portuguesa. Aluno. Ciclo. Disponível em: <http://www.rio. rj.gov.br/sme/.../2caderno. 2009>. Acesso em: 02 set. 2009. 
RIO DE JANEIRO. Secretaria Municipal de Educação do Rio de Janeiro. Descritores avaliativos das provas de português e matemática do terceiro bimestre de 2009. Disponível em: <http://www.rio.rj.gov.br/sme>. Acesso em: 02 set. 2009.

SKLIAR, C. Pedagogia (improvável) da diferença. E se o outro não estivesse aí? Rio de Janeiro: DP\&A, 2003.

SMOLKA, A. L. B. A criança na fase inicial da escrita: a alfabetização como processo discursivo. São Paulo: Cortez; Campinas, SP: Editora da Universidade Estadual de Campinas, 2003.

Texto recebido em 20 de maio de 2015. Texto aprovado em 09 de julho de 2015. 